\title{
A DEMARCAÇÃO PLATÔNICA DE NOVAS FRONTEIRAS EPISTÊMICAS PARA O DISCURSO FILOSÓFICO: UM ESTUDO SOBRE O SOFISTA
}

\begin{abstract}
Maria Carolina Alves dos SANTOS ${ }^{1}$
- RESUMO: No Sofista, mediante os circuitos do procedimento ontológico-binário das divisões dialéticas, Platão busca não somente chegar à verdade das coisas em si, mas, também, a sua correta expressão. A superação das aporias relativas à natureza da linguagem por um tratamento metódico rigoroso, que minimiza suas limitações e inadvertências e a instala numa dimensão transcendente, entre os gêneros do Ser, assegura-lhe o estatuto de discurso filosófico, capaz de dizer aquilo que é como ele é.
\end{abstract}

- PALAVRA-CHAVE: Filosofia antiga; Platão; linguagem; metafísica.

\section{A dimensão transcendente da linguagem}

Platão associa um traço pedagógico, no mais elevado sentido do termo, ao caráter por assim dizer esotérico dos Diálogos, cujos temas mais altos apenas podem ser alcançados ao fim de enormes circuitos dialéticos, por alguns "poucos" (tivsin ojlivgoi) (Platão, Carta VII, 341e). Por outro lado, considera insuficiente chegar a conceber a verdade das coisas em si e não ser capaz de mostrá-la por meio do Lovgo" (Platão, Leis, 966b). ${ }^{2}$ Um inolvidável compromisso com a Filosofia o faz explicitar, metodicamente, as vias que é preciso percorrer para atingir, além do véu que envolve as formas verbais, o significado mais alto nelas cifrado

\footnotetext{
1 Professora aposentada do Departamento de Filosofia - UNESP - 17525-900 - Marília - SP.

2 o[ntw" eijdevnai tav periv th;n ajlhvqeian aujw'n, kaiv lovgw/ te ijkanou" eJrmhneuvein ei\nai ... (Platão, Leis, 966b).
} 
(Platão, Fed., 247d). Procura garantir, aos que resolutamente se empenham nessa longa a[skhsi", que os objetos da reflexão filosófica sejam exprimíveis nos termos desse novo dizer. Usa o verbo eilnai e suas formas nominais oujsiva e o[n didaticamente, como expressão das Formas para figurar (de modo "sensível") as realidades constitutivas do plano inteligível $; 3$ esforça-se por assegurar ao próprio lovgov" uma dimensão transcendente (Parain, 1942, p.8).

Platão vincula os lovgoi dos Diálogos a algo que os ultrapassa - uma mavqhsi" universal os fundamenta e exerce sobre eles inegável primazia para que, minimizados seus limites e inadvertências, ampliados os horizontes de suas significações implícitas, possam cumprir o desígnio filosófico que os fez surgir. É o enfrentamento de insidiosas aporias, relativas à ambigüidade da linguagem, que lhe permite segregar o antídoto contra a natural errância. Inscreve-a numa topografia íngreme vertical, tornando-a apta a acercar-se das alturas apropriadas ao autêntico filosofar, o tovpo" nohto;q e, no último período de sua criação, entrelaça-a firmemente aos gêneros supremos do Ser (mevgista ei[dh) (Platão, Sof., 260a). ${ }^{4}$

Toda especulação desenvolvida a partir do Fedro e, de modo especial, no Sofista, sobre as condições do verdadeiro conhecimento, articula-se à rigorosa investigação dos procedimentos metodológicos, ${ }^{5}$ simultaneamente à proposição de uma "metafísica" da linguagem que possibilite a definição adequada das coisas. Delineia-se, com positividade nova, o quadro instaurador do modo correto de afirmar "o que é", um solo firme que garanta maior transparência à identidade existente entre o pensar e $o$ dizer genuinamente filosóficos.

\section{Para transgredir um inflexível dogma}

\footnotetext{
3 Entretanto, a discriminação dos sentidos dessas ocorrências verbais ou nominalizadas, em si mesmas, e cada uma em relação as outras, comporta várias leituras gramaticais, e é, por isso, carregada de dificuldades. Places (1991, p.50-1) comenta a respeito das ambigüidades do uso da forma oujsiva no livro VII da República, mostrando sua equivalência com ei \nai e tov o[n, e outras relações de associação (com ajlhvqeia) e de oposição (com gevnesi", com dujnami", com dovxa); assim como tov o[n opõe-se, também, a gignovmevnon e a fainovmenon.

4 dia; ga;r th;n ajllhvln tw'n eijdw'n sumplokh;n d lovgo" gevgonen hJmiăhn (Platão, Sof., 259e).

5 Importa a Platão saber, sobretudo nos últimos Diálogos, não somente a natureza da coisa inteligível, diz (Kucharski, 1949, p.3), mas qual o método que pode conduzir ao conhecimento dela. Sobre a querela a respeito da crise do pensamento platônico a partir do Parmênides, Schuhl (1971, p.117) afirma que uma teoria complexa como a das Idéias suscita, normalmente, no espírito do autor, questionamento que o leva a buscar maior aprofundamento e uma sistematização mais aprimorada.
} 
A sofística, com seus mestres itinerantes - educadores profissionais que comercializam uma sabedoria, a competência no discursar -, constituiu movimento intelectual de tão grande envergadura que, na aurora da filosofia pré-socrática, a um só tempo, "seduziu e escandalizou a Grécia", comenta B. Cassin (1990, p.7). ${ }^{6}$ Contemporâneos de Sócrates, os sofistas não são como este filósofo, o amante que não ousa pretender a plena posse do objeto de seus desejos, nem como pensadores originários que meditam sobre o ser ou sobre a natureza. Buscam exercer poder persuadindo juízes, comovendo assembléias, fazendo política, enfim: vangloriam-se de ser excelentes professores de retórica, cujo virtuosismo os tornaria aptos a formar hábeis contraditores em todos os assuntos, capazes de fazer triunfar qualquer tese (ibidem, p.7). ${ }^{7}$

O discurso é meio de troca universal desses mercadores que percorrem o território grego disseminando, com suas tevcna, uma concepção de educação particular, capaz de despertar enorme entusiasmo entre a juventude (Platão, Prot., 314a-315a). Provam, em competições públicas, com eloqüência agonística, ora o sim, ora o não, pelo puro prazer de contradizer (Platão, Rep., 539b-c). Ao defenderem, com brilhantismo, que tudo pode ser afirmado ou negado, antiteticamente, numa mesma tese para eles o discurso falso é impossível -, tornam-se alvo da rigorosa crítica de Platão. Ele os censura sob muitos aspectos, do ponto de vista ético, pedagógico, político (não buscam sabedoria e virtude, porém, poder pessoal e dinheiro), literário (seu discurso é desordenado e enciclopédico), ontológico (não investigam o ser, mas refugiam-se nas obscuras paragens do não-ser): em suma, são antípoda do filósofo, ${ }^{8}$ reduzem-se à categoria do "pseudo" (Cassin, 1990, p.13). ${ }^{9}$

6 Segundo Gomperz (1928, p.34), a sofística não é uma escola de pensamento, nem uma corrente doutrinária particular - a partir das mesmas premissas chegaram a conclusões diferentes, uma vez que a verdade é apenas uma opinião apresentada de modo persuasivo - e sim um conjunto de profissionais que têm, em comum, apenas condições práticas de exercício de seu métier pelo lovgo": são contraditores.

7 Possuem uma mestria da linguagem sob todas as formas, da lingüística (morfologia, gramática, sinonímia) à retórica (estudo dos tropos, das sonoridades, da pertinência do discurso e de suas partes (Cassin, 1990, p.7).

8 No Fedro, Platão procura traduzir o impacto produzido sobre o jovem Fedro pelo discurso paradoxal de Lísias, logógrafo e orador célebre, que defende, brilhantemente, a tese do amor como uma forma prejudicial de excesso, de tal modo que é preferível concedê-lo a um cortejador a quem não ama. Defende, na verdade, segundo a ótica platônica, uma pseudo-sobriedade, um prazer imediatista, expressão de uma razão escravizada à mais baixa forma de desejo, capaz de acarretar a corrupção dos costumes. Além disso, o seu discurso é desorganizado, pode mesmo ser lido do fim para o começo sem que o sentido se modifique, prescinde em seu ponto de partida, de definir o objeto sobre o qual irá discorrer. 


\section{Dos sofistas a Parmênides}

Considerando as proposições defendidas pelos sofistas danosas à Filosofia, Platão dedica parte de sua obra a refutá-las e a depurar o discurso a partir da distinção entre falso e verdadeiro. No Sofista, aponta-os como charlatães imitadores a produzir, com seus truques, simulacros (favntasmai), ilusórias imagens que pretendem semelhança perfeita com o original (Platão, Sof., 268d; Rep., 598e), as quais, se legitimadas, aboliriam a hierarquia que rege as diferenças ontológicas, apagando fronteiras, arremessando-as aos paradoxos do significado, transgredindo as regras da referência (Cassin, 1990, p.15). ${ }^{10}$

Animal esperto - lobo selvagem enganosamente semelhante ao animal mais doméstico, o cão (Platão, Sof., 231a) -, o sofista entrincheirou-se em refúgio de difícil acesso. E de lá, em defesa própria, lança-se diante de seus adversários tentando ludibriá-los, o problema dos problemas: a que afinal se pode dar o nome de imagem (ei[dwlon)? (Platão, Sof., 239e-240a). Com relação às semelhanças (peri; ta;" oJmoiovthta"), afirma o Estrangeiro, é preciso manter-nos sempre em guarda (ajei; poiei'sqai th;n fulakhvn), por tratar-se de um gênero extremamente escorregadio (ojlisqhrovtaton ga;r togevno") (Platão, Sof., 231b). Parecer e assemelhar-se (to; faivnesqai tou to kaiv to; dokei'n) sem ser (ei\nai de; mhv) e dizer qualquer coisa sem dizer verdade (to; levgein me; $\mathrm{n}$ a[ta, ajlhqh' de; mlV são, há muito, fórmulas cheias de embaraço no passado como agora (Platão, Sof., 236e): como falar ou pensar (levgein hJ doxavzei'n) que o falso é real (yeudh'o[ntw" eilnai) (Platão, Sof., 236e), sem estar em contradição (ejnantiologia), ou enveredar pelo perigoso terreno onde o Ser (tov o[n) parece se entrelaçar ao Não-Ser (tov mhv o[n), que Parmênides - pai primordial da filosofia do Ser e da inflexível recusa do Não-Ser propôs a interdição? (Platão, Sof., 237a).

O caráter teatral, intrínseco à criação dos diálogos platônicos, permite a abordagem dessa grave questão sobre a natureza do Não-Ser nos moldes de espetacular perseguição ao "monstro de difícil captura" (Platão, Sof., 223b). O resultado será seu aprisionamento numa definição que lhe

\footnotetext{
9 De acordo com B. Cassin (1990, p.13), a primeira sofística perdeu a guerra filosófica: Platão e Aristóteles reduziram-na ao pseûdos, não-ser, falsificação, a relegaram ao estatuto de má retórica, vazia de sentido. "Expulsão bem-sucedida: a segunda sofística pertencerá, então, não ao corpus dos filósofos, mas dos oradores."

10 Segundo, ainda Cassin (1990, p.15), a história da filosofia metafísica do ser e do sentido é, antes de mais nada, platônico-aristotélica: isso significa que ela deve ter contribuído para compreender mal, cercear ou banir a heterodoxia sofística.
} 
abrange os múltiplos semblantes. Antes, porém, surpreendidos por sua m\&ti", o Estrangeiro e Teeteto, protagonistas do drama, "depõem as armas" para avaliar o impasse que ora se encontram. Permitir que a astuciosa caça fuja, deixando intocado o "problema"? Ou exceder limites interditados por Parmênides? (Platão, Sof., 258c). Ir ao último dos extremos, exercer ação (formalmente) proibida e culpável, a violência (crítica) sobre a rígida tese proposta pela venerável eleata de que toj mhv o[n não é?

"Jamais obrigarás o não-ser a ser"

(ouj ga;r mhv pote tou'to damh' eilnai mh; ejovnta).

(Platão, Sof., 258d)

\section{O mivasma platônico}

Enfrentar o sofista, fazer que a verdade sobre a questão do Não-Ser prevaleça, mas exige um gesto sem precedentes, transgredir tal interdição e livrar-se, de uma vez por todas, do fardo do até então imprescritível dogma? Somente assim, a sedutora arte que ensina a tudo sustentar e justificar, misturando confusamente uma idéia com outra, não triunfará sobre o aprendizado metódico exaustivo de uma qewriva correta das identidades e diferenças relativas a tov o[n em que consiste a ciência do dialético.

Precavidamente o condutor da trama, natural de Eléia e pertencente, ele mesmo, ao círculo de Parmênides (Platão, Sof., 216d), opta por enquanto por deixar em seu refúgio o dissimulado adversário. Dispõe-se a refutar primeiro o venerável filósofo, cuja proposição de um Ser imóvel e indivisível, uno e real (Platão, Sof., 244b-245e), levou a conseqüências assim desastrosas. Polemizar sobre tão espinhoso problema, dizer coisas jamais ditas antes - "o Não-Ser sob certa relação é, o Ser de alguma maneira não é" (tov te mh; o[n wv" e[sti katav ti kai; to; o\n au $\backslash$ pavlin Ww" oujk e[sti ph) (Platão, Sof., 241d) - supõe que se multipliquem os cuidados metodológicos: os lovgoi, que no início da investigação desenvolvem um exercício lógico de divisão, descontraidamente, como numa paidiav, adquirem agora um tom mais dramático.

O desfecho será a mais abominável das infrações na cultura grega de então, o mais ímpio mivasma, o parricídio. É o extraordinário talento pedagógico de Platão, laborando no sentido de propor o Não-Ser com o valor de um cânone universal e de impedir, assim, a redução da Filosofia 
à mera exposição antitética de razões, saber conjectural que permanece sempre inconcluso ${ }^{12}$ e aporético.

\section{A concepção do pantelî Ôn ${ }^{13}$}

O ponto central do complexo enredo do Sofista, tecido pelo embate entre as identidades e diferenças no desenrolar da inquirição, é a constatação da existência de um princípio primordial, o perfeitamente pleno (pantelw'õ $\&$ n, que contém em si a totalidade das generalidades (Diès, 1932, p.88). Em sua natureza heterogênea, coexistem, ao mesmo tempo harmonicamente, a capacidade de agir e de sofrer, de mover-se e de ser movido, como termos mutuamente irredutíveis e inseparáveis. Para haver ciência não é indispensável a existência de algo permanente, de modo que seu objeto não seja arrastado por um fluxo contínuo e sem regra? E, por outro lado, como estabelecer um conhecimento verdadeiro a partir de uma oujsiva perpetuamente imóvel, sem nehuma atividade anímica? O valor dessa concepção do Ser, proposta no Sofista, consiste em defini-lo, concomitantemente, como objeto e sujeito de conhecimento (Platão, Crát., 440a-b). ${ }^{14}$

Platão chega à proposição do pantelw"' \%n analisando dialeticamente o percurso da história das teorias de seus predecessores, dos pluralistas e unitários, aos materialistas e "amigos" das Formas. É a verificação da espessa ignorância em que ainda se encontram, quanto a essa questão principal, a maioria das escolas filosóficas então existentes, que o faz propor, por meio de um raciocínio dialético, a definição que deverá constituir a forma fundamental do saber filosófico. Não significa o refinamento de sua própria teoria? É graças ao procedimento das divisões

12 O metaproblemático é a contrapartida, proposta por Platão, diante do problemático: a Filosofia se arriscaria a permanecer na preliminar função de expressão de prós e contras, sem alcançar jamais nenhuma conclusão, não fora a proposição platônica do ser relacional, na dimensão do metaproblemático. Segundo Bréhier (1953, p.47), a este patamar pertencem intuições originais do pensamento filosófico, tais como a visão platônica do Bem, as idéias claras e distintas de Descartes.

13 De acordo com Diès (1932, p.81-2), o pantelw’" o[n não é o Todo (tov pa‘n ou t£v p v t ), nem o Ser (tov o[n ou ta; o[nta) Para Brochard (1974, p.24), ele designa o universo tomado em sua totalidade (tov pa'n), e o traduz por ser total, ser completo, que abarca e contém todas as realidades, ao mesmo tempo, isto é, as Idéias. Robin (1957, p.107) traduz pantelw"'\$n como o que é completamente, o ser em sua total plenitude.

14 Platão resume aqui, sucintamente, o argumento desenvolvido no Crátilo sobre as condições em que a ciência é possível (440a-b). 
ontológico-binárias que, pouco a pouco, a conversação estabelece demarcações novas no território do Ser: traz à luz o amplo quadro dos entrecruzamentos estáveis de suas relações categoriais, determinações recíprocas cuja matriz é a comunidade de gêneros supremos, que engloba, ao lado do jogo oposicional do Movimento e do Repouso, o da identidade do Mesmo e da contrariedade do Outro (to; e[teron), no qual a diaivresi" fundamentará a realidade do Não-Ser.

A apreensão da positividade da natureza do Não-Ser, essencialmente diferente da do Ser, para além dos pontos ambíguos impostos como limítrofes pela sofística, permitirá a Platão infringir-lhe derrota filosófica quanto à problemática impossibilidade do erro. Havendo Não-Ser nas coisas e nos discursos, a natureza dele será também, em sua extrema alteridade, plenamente capturada pela linguagem ao término do Diálogo, concomitantemente à circunscrição correta da singular individualidade do sofista após exaustiva perquirição.

\section{Pequena história crítica da ontologia dos primeiros filósofos}

Fiel às exigências do seu pensar, Platão situa a própria filosofia, sinoticamente, na confluência das correntes matinais, abarcando tudo o que nelas há de essencial, integrando-as à trama que constitui o estofo do complexo conjunto de suas teses. Ao lado da hipótese da existência de realidades imutáveis e separadas dos "amigos das Formas" (para os quais tudo é repouso), admite, simultaneamente, dos "filhos da terra" (para os quais tudo é movimento), a teoria heraclítica do eterno fluxo de todas as coisas. Dessa fusão, cujo alcance e significação são fundamentais à apreensão da natureza do Não-Ser, surge tríplice formulação: há Movimento, há Repouso e o Movimento não é o Repouso. Para isso, inclina-se sobre o que foi dito antes, desde os séculos precedentes, fazendo história crítica da ontologia antiga (Platão, Sof., 242c). Revolve esse terreno desde as mais profundas raízes, indagando passo a passo pelo Ser (e não pelo Não-Ser), primeiro do ponto de vista da quantidade (pluralistas e monistas) (Platão, Sof., 242e-243d) e, em seguida, quanto à qualidade (sustentada pelos materialistas, idealistas, mobilistas e imobilistas) (Platão, Sof., 246a-249d). É um acontecimento radical, instaura uma ruptura no cerne do saber metafísico instituído até então, com a constatação da impotência de todas essas filosofias em fornecer a definição adequada para o Ser. 


\section{Crátilo, discípulo infiel a Heráclito}

No Crátilo, Sócrates contesta o realismo exacerbado desse discípulo de Heráclito, para quem a linguagem possui relação imediata, necessariamente adequada à coisa a que se refere. Diante de sua tese "conhecer os nomes é conhecer as coisas" (Platão, Crát., 453d), argumenta que as denominações imitativas - as sucessivas abstrações mediante as quais ocorre a união de um nome com a coisa - podem ser bem ou mal feitas, de modo que o acordo essencial entre eles nem sempre se estabelece. A proposição de Crátilo, por um lado, possui denominador comum com a doutrina da sofística segundo a qual um discurso falso jamais poderia ser concebido ou pronunciado. E, para contestá-la, o dialético apóia-se (neste Diálogo) na hipótese da realidade das essências inteligíveis, imutáveis, eternamente estáveis: proclama-as fundamento do próprio discurso (Platão, Crát., 438c), a partir do qual apontará seus limites, um curto alcance na solução do problema das relações entre a linguagem e o conhecimento verdadeiro.

Por outro lado, a atribuição de uma denominação unívoca, fixa, expressão fiel da natureza das coisas defendida por Crátilo, contraria mesmo a doutrina heraclitiana do pavnta Jrei, que faz do movimento a fonte originária de todas as coisas, interpretando-as no sentido vulgar (nãoheraclítico) ao excluírem-lhe a potencialidade contrária e a transmutação recíproca entre opostos: o mobilismo transforma-se, assim, num absoluto relativismo. Por tomar o que está em perpétua mudança como referencial, o ato de nomear apreende do real apenas percepções sensíveis e confusas que nada podem qualificar de modo justo. Acaba por conduzir a uma espécie de misologia em relação aos nomes, ao propor a renúncia a eles e a utilização exclusiva dos gestos como meio de expressão: Crátilo limita-se a agitar o dedo. ${ }^{15}$

Contra a rígida unilateralidade da posição de Crátilo, Platão afirma, no Teeteto, a importância e o grande valor dessa teoria de Heráclito (ouj fau'lon lovgon) (Platão, Teet., 152d-e), o fluxo universal num texto em

15 Dessa perspectiva, o mesmo se poderia dizer do sofista Antístenes - filho da terra e também inimigo das Musas e da Filosofia - com seu nominalismo estático (as coisas devem ser consideradas em sua individualidade separada), acaba por se identificar a seus piores inimigos, os idealistas. Partidários da inércia universal, defensores da impossibilidade da ligação entre os elementos, toda tentativa de definição, para eles, nada mais é que uma perífrase, remete apenas a certas qualidades que possuem e não à essência que está contida nos nomes, aos quais, portanto, só se pode atribuir essa mesma fórmula, que lhes é própria (Platão, Sof., 232c; Aristóteles, 1043b, 26, 1970). 
que ela aparece perfeitamente conectada com a tese da identidade dos contrários e com a questão da ojrqovth" dos nomes:

nenhuma coisa é em si mesma e por si mesma uma só, e tu não poderás dar um nome corretamente nem a um ser qualquer, nem a uma qualidade: se denominada grande resulta que poderá aparecer também pequena, se pesada, leve e assim em tudo o mais, de forma que nada é uno, ou algo determinado, ou como quer que seja. Justamente por mudar de lugar, por mover-se, pelo misturar-se das coisas entre si é que se torna tudo aquilo que dizemos existir; as quais em troca, nós com uma expressão correta dizemos que são, já que nada é, sempre se transforma.

Ao rearticular, em toda sua amplitude, a vinculação necessária entre o processo do devir universal e a unidade permanente que subsiste no eterno conflito entre opostos - o fluxo identifica-se ao trânsito constante do convergente ao divergente, aspectos de uma mesma coisa intercambiando-se reciprocamente -, Platão demonstra captar, concomitante à glorificação da discórdia, do combate, do contínuo fluir que a sabedoria heraclitiana propugna, uma lei inevitável, a transmutação recíproca entre opostos em cada ser, sem exceção, nem interrupção: a permanência na mudança. É o que impede o turbilhonamento desordenado de todas as coisas, garante a perenidade e a unidade da bela harmonia invisível, condicionante e explicativa da aparição do visível. ${ }^{16}$

Assim, o essencial na concepção formulada pelo Lovg?o heraclítico, segundo Platão, é a relação estável de coincidência e identidade que os opostos, em contínua mudança, mantêm entre si, de modo permanente. Se há tal inseparabilidade e implicação recíproca entre forças antagônicas, pode-se afirmar que nada é somente ele mesmo, mas é também seu contrário, que o uno é múltiplo e o múltiplo é uno (Platão, Sof., 242c). A presença constante da antinomia convergente-divergente, de um para outro, de modo recíproco, é requerida entre todos os seres; e, para esses opostos que se incluem mutuamente, que são, pois, uma e mesma coisa, nesse processo sucessivo que é a transmutação recíproca, no dizer de Heráclito (contra o de Crátilo), um nome pode significar, a um só tempo e sem erro, coisas contrárias: bivo" indica vida e morte; zwh é princípio de vida e de morte; os pontos da circunferência são, um a um, concomitantemente, o princípio e o fim do círculo (Platão, Fr., 67, 88).

16 O espírito do heraclitianismo é o da mudança, mas de uma mudança que salva a harmonia no seio das alterações e das discordâncias (Gaudin, 1990, p.277). 


\section{Platão é heraclitiano}

Somente com a aceitação desse dinamismo, fluxo ininterrupto de tensões opostas, intrínseco a todo existente, apontado por Heráclito, será possível a Platão chegar a uma conceituação adequada do Ser. A busca multiplicou as exigências para o enfrentamento dos inúmeros obstáculos que o sofista, com astuciosa destreza de pensamento e de discurso, criou para esquivar-se à própria definição. $\mathrm{O}$ maior deles, a impossibilidade de dizer que ele possui apenas imagem ou aparência de ciência (desde que o "Não-Ser não é, e o erro é impossível"), está sendo removido mediante cerrado questionamento desse pressuposto de Parmênides, que toma por base a doutrina heraclitiana da luta dos opostos e da harmonia dos contrários. O esquema da oposição entre o Um e o Múltiplo, empregado para sistematizar a relação antinômica entre o sensível e o inteligível, será desmontado com a elaboração de uma concepção em que eles se relacionam e completam-se mutuamente. ${ }^{17}$

Assim, da mesma maneira que o Um de Heráclito é perpetuamente Múltiplo, Platão introduz um certo mobilismo e multiplicidade em sua definição do Ser ao classificar as mais altas Formas, aquelas que constituem a comunidade entre os Gêneros - o Movimento, o Repouso, o Mesmo, o Outro -, na qual ele próprio é maior e principal (Platão, Sof., 243d). ${ }^{18}$ Diz o Estrangeiro em suas investigações dialéticas que, de algum modo, o Ser não-é e o Não-Ser é e que ambos, enquanto opostos, coexistem, penetram tudo e também a si mesmos reciprocamente: o Ser não se identifica, por inteiro, a nenhum desses Gêneros, e é, pois, dessa diferença, que surge o Não-Ser. A tarefa crítica, empreendida contra as antigas doutrinas do Ser, conclui com a afirmação de que ele é aplicável a tudo, comporta-se como Repouso, como Movimento, como Mesmo, como Outro; e que, ao definir-se como o mesmo que si mesmo, opõe-se à infinidade de seres que ele não é, os não-seres (Platão, Sof., 254b): “Quantas vezes os outros são, tantas vezes o Ser não-é". ${ }^{19}$

O Não-ser não é, portanto, o contrário absoluto do Ser, nem tampouco o nada, apenas é outra coisa que o Ser, ou seja, é o Outro. E, ao exercer a função diferenciadora - o ser do Não-Ser é ser Outro -, parti-

17 Platão pretende mostrar que um mesmo objeto sensível pode receber diversos predicados e, assim, participar de diferentes Formas, do mesmo modo que as Formas participam uma das outras: um homem pode ser dito não somente homem, mas também grande e bom; o Movimento pode ser denominado ser, embora possua incompatibilidade essencial com outro ser, que é o Repouso, e é a Forma principal, o Ser, o Um, que unifica a multiplicidade delas.

18 tou' megivstou te kai; ajrchgou'. (Platão, Sof., 243d). 
cipa do Ser, é condição da possibilidade de apreensão do modo próprio de sua existência (Platão, Sof., 258b-e). Ele veio à luz a partir do jogo dialético de oposições entre o Ser e o Outro, é apreendido como o diferente do Ser, possui uma diferença positiva, não inferior (em ser) a nenhum outro Gênero: o Não-Ser não é tão real quanto o Ser?

É a investigação sobre a pouco explorada natureza do Ser que permite a manifestação do Não-Ser - ele surge quando o Ser se retira - como cada fração do Outro que se opõe ao Ser (Platão, Sof., 258a-d). Há Não-Ser nas coisas e nos discursos: a cada afirmação (positiva) do Ser corresponde a infinidade de negações que essa asserção acarreta, a multidão inumerável de existências que não são o Não-Ser ainda que elas sejam, e que ele não é, ainda que, de alguma maneira, ele seja (Diès, 1932, p.127). Sobre essa mútua relação de Gêneros, o discurso correto deverá se fundamentar, embora possa colocar ligações onde não podem existir e, nesse caso, dizer algo diferente do que ele (o Não-Ser) é e ser falso.

Imitar as crianças que querem, ao mesmo tempo, duas coisas opostas (Platão, Sof., 248d) é a metáfora com a qual Platão indica a amplitude da nova visão que está construindo do Ser. Fórmula unificadora de doutrinas opostas, concilia os que propõem o Repouso e a Unidade como fundamento último do real, aos partidários do perene Movimento da multiplicidade das coisas existentes. O pantelw" \%u tem inteligência, alma, vida e movimento (Platão, Sof., 249c-d) e, por sua natureza, mantém-se em comunidade (koinwniva) com todos os seus gêneros principais. E, da mesma maneira que estabelece com eles mútua interpenetração, o Mesmo e o Outro misturam-se entre si, por oposição ao Movimento e ao Repouso: estes, por incompatibilidade, não podem participar um do outro (mhdemiva koinwniva) (Platão, Sof., 255a) constituindo, porém, sumplokh; com o Ser. ${ }^{20}$

19 kai; to; o[n a[r j hJmi'n, o \{sapevr ejsti ta; a[1la, kata; tosau"ta oujk e[stin (Platão, Sof., 257a). Na República, Platão definirá o Não-Ser como algo incognoscível (477a); e, no Parmênides, como aquilo do qual não existe nem definição, nem denominação, nem ciência, nem sensação (142e). E, no Sofista, onde sua realidade é estabelecida, claramente, de acordo com G. E. M. de Pinotti, não seria o Não-Ser em si mesmo (kaq j autov), o que absolutamente não-é (mhdamov" o[n), o qual Parmênides declarou impensável: desse, Platão se ocupa em 237b-239c, mostrando que é absolutamente impossível fazer-lhe qualquer alusão. Trata-se de um Não-Ser relativo aos seres (pro" o[nta), um Não-Ser que não é contrário, mas apenas Outro, diferente (ajll [eteron movnon) (Platão, Sof., 257b, 258b). Sendo assim, Platão estaria refutando no Sofista mais a herança sofística que o dictum paternal (Pinotti, 1994, p.153).

20 Segundo Gaudin (1990, p.205): “Por que, pois, Platão introduz, ao lado dessas três 'Formas', cuja universalidade parece óbvia, o Repouso e o Movimento que, à primeira vista, parecem originar-se da Física? Os dois gêneros, o Movimento e o Repouso, trazem consigo o peso da fuvsi" inteira, enquanto os três outros condensam todas as aporias que o Parmênides desenvolve a partir do Um e 
O pantelw"' o[n, ora proposto, tem como característica principal englobar em si todas as alternâncias, a mobilidade e a permanência, a unidade e a pluralidade (Platão, Sof., 248e-249c). ${ }^{21}$ E se o Movimento e o Repouso não podem misturar-se entre si, associando-se a eles, o Ser torna cada um outro que o Outro e, também, o Mesmo que ele mesmo (Platão, Sof., 250a-252e). Para que uma ciência seja suprema, segundo Platão, é preciso que em seu lovgo" sobre o Ser e o Um - contra a rigidez do discurso dos Eleatas - estejam presentes a multiplicidade e a relatividade. Há, entre as Formas do Ser, uma multiplicidade de relações necessárias, sejam elas de pertinência ou de exclusão; e o Não-Ser, enquanto equivalente ao Outro, do mesmo modo que o Ser, alia-se, também, a todas elas sem exceção (Platão, Sof., 259a): embora não seja um $6^{\circ}$ Gênero, não tem menos ser que nenhum deles.

\section{Crítica ao eleatismo radical}

Para adquirir adensamento, rigor e força imagética, a concepção do pantelw"' \%n exige, ainda, verdadeira antinomia em torno das premissas dos enigmáticos "amigos das Formas". ${ }^{22}$ No Parmênides, Platão atribuíra ao grande defensor da Unidade a tarefa de criticar o dualismo radical presente na base de sua Teoria das Formas. O exame da primeira parte desse Diálogo busca as conseqüências da separação total entre o sensível e o inteligível e o da segunda, as análises dialéticas mostram a impossibilidade da existência da pura Unidade isolada da Multiplicidade. Por meio desse laborioso jogo (pragmateiwJdh paidiav) (Platão, Parm., 137b) ataca, frontalmente, não apenas a Parmênides, porém a própria doutrina, naquilo que se inspirou nele. $O$ desfecho da estafante tarefa é a afirmação da esterilidade do eleatismo e da necessidade de flexibilizar a hipótese de

do Ser". De acordo com Strycker (1953, p.55-6), pode-se invocar, inicialmente, um motivo histórico, o emprego que o eleatismo fez dessas noções. Mas uma razão bem mais decisiva é que Platão as fez intervir em um estágio anterior da discussão e mostrou sua significação fundamental para a ciência suprema: o Repouso designa a determinação intrínseca de cada essência, o Movimento sua cognoscibilidade ( $248 \mathrm{~d}$-e) e as duas formas juntas caracterizam o objeto em relação ao sujeito cognoscente...

$21 \mathrm{Na}$ República, emprega a mesma terminologia: to; me;n pantelw' o[n pantelw'"gnwsto;n (o que possui existência absoluta é absolutamente cognoscível) (Platão, Rep., 477a), porém, afirma a incognoscibilidade do Não-Ser (mh; o[n de; mhdamh' panth' a[gnwstovn).

22 Segundo F. M. Cornford (1935, p.242), alguns os consideram os primeiros platônicos ou o Platão mais antigo. 
que as coisas inteligíveis não são passíveis de participação (Platão, Parm., 129a-d). ${ }^{23}$

No Sofista, a partir do questionamento da proposição central dos "amigos das Formas" - a separação absoluta entre a realidade (oujsiva), o que permanece sempre o mesmo, objeto do intelecto, e o devir (gevnesi"), variável de acordo com o sujeito e as circunstâncias, objeto da sensação -, Platão chega à explicitação do paradoxo nela contido. O que constitui o aguilhão do qaumavzei'n do filósofo é a asserção de que, para haver ciência, é preciso os objetos absolutos estarem inteiramente subtraídos à relatividade das coisas sensíveis e do devir, em razão de sua transitoriedade (Platão, Féd., 75a; Sof. 248a-249a). A separação total da realidade suprema não implica tal inescrutabilidade que inviabilizaria a formulação de toda proposição filosófica? É para melhor colocá-la nos termos de um empreendimento crítico, que o olhar agudo do dialético distinguirá nela tríplice impossibilidade discursiva: a participação das coisas nas Formas (condição da percepção sensível e do julgamento da percepção); a participação do espírito nas Formas (condição da intuição dos conceitos) e, ainda, a participação das Formas entre si (condição da relação entre os conceitos). Estivesse a Forma inteiramente separada das coisas, dos espíritos e das outras Formas, encerrada em si mesma e incomunicável, redundaria numa crise extrema da experiência do filosofar com a abolição do próprio discurso: seria impossível raciocinar ou falar sobre qualquer coisa, acarretando múltipla ofensa à harmonia, às musas e à Filosofia. $^{24}$

Privar-nos disso (de assegurar ao discurso um lugar entre os gêneros do Ser) seria, com efeito - perda suprema - privar-nos da filosofia. ${ }^{25}$

Na conclusão da segunda parte do Parmênides, cujo objeto principal de indagação é o lovgo", Platão aproxima-se das proposições do Sofista ao afirmar que o Um não está separado, em pleno isolamento, diante do que o sujeito cognoscente seria simplesmente inoperante. Em suas relações consigo mesmo e em suas relações recíprocas, constitui uma mistura de Ser e de Não-Ser, de maneira que "o que é" tem participação no Não-Ser, e "o que não é" tem participação no Ser (Platão, Parm., 162b): portanto, ambos, Ser e Não-Ser, pertencem ao Um. O árduo exercício, mediante o

23 De acordo com Parain (s.d., p.159 ss. e 193; 1942, p.32), a discussão do Parmênides é já uma rigorosa reflexão sobre a natureza da linguagem, uma dura prova a que o logos é submetido. 24 a[llw" te oujk ejmmele" kai; dh; kai; pantavpasin ajmouvsou tino;" kai; ajfilosovfou (Platão, Sof., 259e). 
movimento quase geométrico de suas afirmações e negações, estabelece as fundações da teoria platônica do pensamento negativo: visar o Ser é apreendê-lo, necessariamente, sob o fundo do Não-Ser. Essa teoria erradica da "hipótese" das Formas (na expressão de E. Bréhier, 1967, p.102 e 108) o estatuto de "modelos separados" e refuta, decisivamente, o que se poderia chamar de "monismo ontológico" dos "amigos das Formas". ${ }^{26}$

As ressonâncias desse exaustivo exame perceptíveis no Sofista constituem o pano de fundo da especulação que soluciona as aparentemente insuperáveis dificuldades na formulação da doutrina do Não-Ser. Assim, a conclusão quanto ao problema das relações entre coisas e Formas, abordada no Parmênides, é aqui aplicada nas relações das Formas entre si (ainda que, no primeiro caso, tais nexos não estejam em simetria tão exata como no segundo) (Brochard, 1974, p.148). Somente, então, será possível configurar como errôneos os ambíguos lovgoi sofísticos que enunciam, com sua arte não-divina mas humana (Platão, Sof., 268d), a inviabilidade de pensar ou dizer falso, ao falar as coisas de modo diferente do que são (e[tera tw'n o[ntwn) (Platão, Sof., 263b).

\section{O ser do lovgo"}

A inovadora associação do Ser ao Movimento - a partir da qual torna-se possível falar do Não-Ser como alteridade - é o corolário que permitirá, também, a definição conveniente do próprio discurso. Definir

25 pr;o" to; to;n lovgon hJmi'n tw'n o[ntwn e[n ti genw'n ei\nai. Touvtou ga;r sterhqevnte", to; me;n mevgiston, filosofiva" a[n stereqei'men (Platão, Sof., 260a) Comenta Dias (s. d., p.12): "Ao tentar desmontar seu próprio platonismo, Platão teria se tornado o primeiro antiplatônico, o pioneiro de uma infindável série de pensadores que se perfilam na história do pensamento como arautos de novas partilhas no campo epistêmico, definitivamente delimitado por ele em suas discussões sobre o Ser. E, ao reinterpretarem a história da Metafísica, esses pensadores crêem descobrir que a tarefa que Nietzsche propôs aos séculos vindouros e que fizeram sua é, aparentemente, a mais velha das tarefas. A história do pensamento metafísico surge-lhes não apenas como a história das metamorfoses de Platão, mas, também, como uma espécie de catálogo das sucessivas tentativas de inversão do platonismo. Quem, afinal, foi Aristóteles, senão o primeiro a tentar inverter o mestre, ao procurar transpor para a realidade imanente a idealidade transcendental de Platão? Mais ainda: não terá sido o próprio Platão, um Platão II, sempre presente como o reverso do Platão I, como um objetor de consciência a indicar, em duas direções diferentes e opostas, as alturas solares no Parmênides, as profundidades cavernosas no Sofista, os pontos por onde 'pegar' o platonismo e fazê-lo tropeçar? Não foi Platão o primeiro antiplatônico...?"

26 Mediante uma reflexão sobre a formulação da concepção do ser relacional, afirma Pacci (1971, p.41), é possível superar o dogmatismo ontológico que a tradição atribui com tanta insistência a Platão. 
algo não é recompor sua fórmula com conceitos, em número suficiente, de modo a instituir o sistema das diferenças, o que permite dizer a coisa em sua identidade? O discurso tem essa propriedade exatamente por sua natureza própria, a qual é participante do mundo inteligível (e não do sensível). Por essa razão, ele não é um objeto particular (como querem Crátilo e os sofistas), mas um gênero do Ser (Parain, 1942, p.182-3); pertence, pois, àquela mesma comunidade à qual o Não-Ser está integrado também como valor necessário. Ainda que o Não-Ser não seja um Gênero como os outros, como dissemos, está disperso de tal maneira entre eles (Platão, Sof., 260b), que todos os que participam do Ser podem, de certo modo, ser chamados de Não-Ser (um Não-Ser não-absoluto, relativo enquanto Outro, cuja indeterminação é circunscrita por intermédio do Ser). É assim que Platão garante ao Não-Belo, ao Não-Justo, um lugar no discurso ao lado do Belo e do Justo, em relação aos quais mantém uma diferença que pode ser considerada positiva: o desafio a Parmênides levou-o além dos limites estabelecidos (Platão, Sof., 258b) por ele mesmo, pois não é a própria natureza do Ser que permite a manifestação do Não-Ser lovgo" do filósofo?

Progressivamente, a reflexão do Sofista tornará mais claro que uma correta teoria do conhecimento não pode ser desvinculada de uma "metafísica" da linguagem (ou de uma linguagem "metafísica"). A inédita visão do Ser em sua transcendência, marca do realismo platônico cujo fundamento é a conformidade de "o que é dito" com "o que é" (Platão, Sof., 263b), é instauradora de uma nova concepção da linguagem que obtém sua verdade a partir de algo que não é ela e que a ultrapassa.

\section{O lovgo" e a comunidade dos Gêneros supremos do Ser}

A característica distintiva do lovgo" é ser a sumplokhv entre nome (o) noma) e verbo (rhma, constituindo assim um enunciado que não os enumera simplesmente, mas procede à combinação adequada dos conceitos (sumplokhv tw'n ei[dw'n). Dizer algo a propósito de algo (tiv periv tinov") - seja afirmativa ou negativamente em relação ao presente, ao passado ou ao futuro, de maneira sintática e semanticamente correta ("Teeteto está sentado"), ou de modo absurdo e falso ("Teeteto voa") são regras que lhe imprimem legítima configuração. ${ }^{27} \mathrm{O}$ primeiro, o mais elementar e breve dos discursos (prw'th sumplokhv), que associa o sujeito concreto, agente, designado por um substantivo, ao qual se atribui ação expressa por um verbo (Platão, Sof., 262a-263a), é um átomo inteligível, 
cuja fórmula é governada pela sintaxe da língua grega. ${ }^{28}$ Em nome dele, Platão recusa enunciados tautológicos (incapazes de fundar um lovgo" verdadeiro) desde que sua identidade própria é adquirida por pertencer a uma comunidade: baseando-se numa lógica de atribuição, estabelece-lhe a função de discorrer, entrelaçando nomes e verbos num tecido homogêneo, que codifica, em proposições plenas de dizibilidade, as relações de vizinhança e harmonia ou de dessemelhança e desacordo entre as Formas (Platão, Sof., 262d): o lovgo" é um gênero porque, tal como eles, seu ser é relação e sua obra é koinwniva.

A inscrição da linguagem entre as categorias supremas, fonte de todo valor, não traz à luz sua função e sentido metafísicos? Cabe-lhe desvelar toda uma rede de relações regulares, a grande teia de conexões perfeitamente interligadas, desses cernes irredutíveis de significância, e declarar o Princípio de suas combinações, em asserções adequadas, quanto ao lugar que cada uma delas ocupa em relação à verdade. Nos últimos Diálogos, não mais é suficiente dizer de uma Forma que ela é autov kaq jautov, mas que se dêem indicações relativas a seu encadeamento com as demais, porque o lovgo" platônico postula uma identidade aglutinadora, cujos componentes essenciais, a estabilidade e a "impessoalidade" (capacidade de relação com paradigmas transumanos universais), garantem-lhe direito de cidadania nessa organização harmônica que é a comunidade dos gêneros: integrado nela, participa, interage com a suprema realidade com pertinência, segundo as leis específicas dessa coletividade ideal.

E, para traduzir essa concepção da correção (ojrqovth") do discurso filosófico, destinado a expressar o alcance de sua ontologia, Platão apóia-

27 O preceito estabelecido no Sofista, segundo o qual é possível dizer o Não-Ser, havia sido preludiado de certo modo no Crátilo, onde Sócrates admite, já, a possibilidade de acrescentar ao nome uma letra que não convém e de fazer o mesmo em relação ao nome em um enunciado (o[noma ejn lovgw/), e em um enunciado sem relação com as coisas no discurso (lovgon ejn lovgw/ mh; proshvkonta toi'" pravgmasin). Isso não é impedimento para que se possa nomear, enunciar um objeto, desde que nele se encontre o caráter distintivo (tuvpo") do qual se fala (Platão, Crát., 432e): para indicar isso de que se fala, nos servimos do nome, que é o instrumento didático (didaskalikovn), diacrítico (diakritikovn) dessa verdade exterior e superior a ele, a oujsiva (Platão, Crát., 388bc) (Pinotti, 1994, p.170).

28 Platão transporta o aspecto analítico-sintético da ciência gramatical de seu tempo para a ciência dialética. As letras do alfabeto, elementos indivisíveis (tav stoiceija) (Platão, Crát., 424de) com os quais o gramático trabalha, compondo e decompondo sílabas e, com elas, as palavras funcionam como modelo para o exercício de análise e síntese do dialético. A combinação possível entre as letras (há aquelas que se associam e as que não combinam) (Platão, Sof., 252b - 253a) é transferida para as essências: da mesma maneira que as vogais, elementos privilegiados da linguagem que operam a ligação entre todas as demais letras, os gêneros supremos o fazem entre as Formas (Platão, Sof., 253c) (cf. Joly, 1974, p.124-7). 
se num idiotismo da própria língua, uma fórmula corrente e simples: dizer a verdade é dizer "o que é" (levgein tav o[nta); sustentar o erro seria proferir "o que não é" (levgein tav mhv o[nta), atribuindo às coisas algo que não lhe pertence. ${ }^{29}$ Ao dialético cabe conseguir abarcar, com sucesso, em seu lovgo", a oujsiva de cada coisa, que consiste na verdadeira explicitação de "o que ela é" (Platão, Rep., 534b; Cornford, 1935, p.270).

Diante da multiplicidade de relações abstratas e necessárias existentes entre as Formas puras, o discurso que as evoca e as simboliza em suas múltiplas combinações mostra ininterruptamente dupla face: uma voltada para o Ser que se esforça por representar; outra, voltada para a negação que exerce por não se identificar por inteiro com ele. Ou seja, o discurso refere-se a algo que tem primazia ontológica sobre ele, a oujsiva (Platão, Sof., 249c-255a) e, sendo o mesmo que ele mesmo (isto é, logo"v), é outro que ela (pois nem haveria ele mesmo se não houvesse esse outro diferencial, a oujsiva). Essa não-identificação ressalta o direito de existência do negativo, na trama do seu tecido, como diferença, ainda que afirme do Ser aquilo que ele "é", no sentido metafisicamente forte do termo. ${ }^{30}$ Assim, o discurso possui, por natureza, lugar privilegiado entre o pequeno número de Gêneros soberanos, mantendo sua alteridade, ainda que subordinado a esses princípios de razão dos quais deve dizer de modo pertinente a essência, delineando, num nível teórico, a fisionomia peculiar ao realismo platônico nos últimos Diálogos.

\section{A eujporiva metodológica}

A teoria da conformidade, como nova formulação do princípio de identidade, a exata adequação entre "o que é dito" e "o que é", fundamenta a concepção de discurso filosófico que Platão estabelece no Sofista. Viajando pelos argumentos (dia tw'n lovgwn poreuvesqai) (Platão, Sof., 253b; Rep., 510b), urde solidamente enunciados acerca das eildh, que fazem cintilar, com precisão, seu sentido essencial. A duvnami" do método, que toma por princípio a koinwniva entre elas, distingue-se com \% pisthvmh de relação, de especificação, de síntese ontológica, que faz do discurso um organismo vivo, bem composto, com capacidade de regeneração contínua do próprio tecido (Platão, Fedro,

\footnotetext{
29 ta; mh; o\nt!a\}ra wJ" o\}nta levgei (Platão, Sof., 263p).

30 Desse ponto, em definitivo, afirma Nadal (1984, p.32 e 18) que Platão não poderia contradizer Parmênides, pois pensar negativamente o existente não poderia se confundir com pensar o Não-Ser.
} 
265d). No decorrer dessa investigação sobre o lovgo", os exames da natureza do Ser e da mais alta das ciências (th"' megivsth??? a dialética (Platão, Sof., 253c) aparecem estreitamente entrelaçados. Os modos de pensamento do "puro e reto amante da Filosofia" mostram-se inseparáveis dos modos de ser de seu ojrganon, seja no movimento de apreender, de maneira direta e imediata, as leis que regem as compatibilidades e incompatibilidades entre as Formas supremas; seja no movimento de classificá-las no gênero conveniente, sem negligenciar as diferenças ou confundir as semelhanças, a partir de um critério transcendente tomado como fundamento.

Embora o espírito da teoria da participação seja pioneiro - como tentativa de fornecer um quadro coerente da estruturação ontológica do mundo inteligível -, coaduna-se, perfeitamente, com uma tendência (ou exigência) característica do pensamento grego, desde tempos arcaicos, obedece à lei da bipolaridade, segundo a qual a realidade toda pode ser reduzida a duplas antitéticas (o quente e o frio, o par e o ímpar, o visível e o invisível), que funcionam como princípio de ordenação e de simplificação (Schaerer, 1969, p.292). É sob essa herança que Platão concebe a dialética, engendra o procedimento das divisões dicotômicas, cuja sutileza e rigor lhe proporcionam a superação do nível da conjectura e a aquisição de um conhecimento abrangente a respeito do Ser: a arte de dividir depende, em larga medida, de uma idéia exata da natureza da coisa que, por sua vez, decorre do mais elevado ato contemplativo, a imediata compreensão, e, também, da posse de um conjunto de divisões anteriormente efetuadas pelo contínuo exercício de suas habilidades (Crombie, 1979, p.76).

A dialética é assim considerada, no Sofista, ciência rigorosa do Ser (Platão, Sof., 253c), de acordo com a qual, não sendo seu objeto absolutamente imóvel, separado ou incognoscível por sua transcendência ativa, mantém íntima relação com a totalidade dos novhta que compõem o plano inteligível. E assim, por ser primaz, não se pode dizer que o Ser supremo funcionaria como uma espécie de motor demiúrgico que dá nascimento às demais Formas e cujo processo a "démarche" dicotômica é capaz de recuperar, explicitando de que modo elas estão presentes em seu âmago. Num labor incessante e meticuloso, dialogando consigo mesmo, o pensamento aperta o cerco, põe-se em guarda contra a ambigüidade característica das similitudes. O complexo jogo classificador despoja a qewriva, duramente conquistada, de tudo que possa ter em comum com outras até que, por uma rede sem lacunas, "diaireticamente", faça evidente (ajpofaivnw) sua natureza específica. O texto resultante da "ciên- 
cia dos homens livres", 32 tecido com grande número de nomes e verbos, entrelaçados de modo a determinar alguma coisa (ti peraivnei) (Platão, Sof., 262d), seja negativamente, seja afirmativamente, chega ao ponto soberano, à definição: por meio desse crivo que desvela a multiplicidade contida em cada essência, foi possível a Platão reproduzir, de modo conveniente (ainda que sem exauri-la), a realidade inteligível naquilo que ela é, uma idealidade pelas nervuras dessa trama discursiva perfeita, arquitetada para desmascarar o sofista.

\section{O discurso do filósofo}

O objeto principal da discussão no Sofista, questão de grande importância explicitada já em sua abertura - "quem é ele e por qual nome ele é chamado" (Platão, Sof., 217a) -, é "euporeticamente" alcançado ao final do Diálogo. O êxito de tão extenuante pesquisa não se deve à ciência que serviu de guia através dos lovgoi, que permite conhecer as coisas diretamente em sua constituição mais íntima e sistematizar, com boa nitidez, suas semelhanças e diferenças? O drama, que se desenrola na dilemática busca, é o do Mesmo e do Outro, de um Outro que é, aparentemente, quase o Mesmo tal qual um sósia a um só tempo diferentes e perigosamente semelhantes e, sem dúvida, rivais (Pessanha, 1997, p.24). Na medida em que a conversa, que enfocara de início o sofista, desenvolve-se iluminando com abundantes referências o seu reverso, o filósofo delimita também a morada habitual de cada um.

A argumentação dialética sutilmente despoja o sofista e o filósofo de tudo que têm em comum, turvas semelhanças, tornando mais patente a especificidade própria àquele que se encontra dissimulado nas obscuras paragens do Não-Ser, tão bem acomodado lá como se estivesse em sua própria casa; e, ainda, a deste outro, cujos pensamentos estão sempre voltados à luminosa natureza da realidade transcendente, no âmbito da qual transita com familiaridade. Em ambos os casos, é difícil divisar claramente esse lugar em que é preciso procurá-los: um, em razão do caráter sombrio e inexpugnável de seu esconderijo; o outro, porque a região em que vive é demasiado brilhante e o olho das almas comuns apenas consegue fixá-lo com extremo esforço (Platão, Sof., 254 a-b). Por estar bem preparado, o dialético discerne não só o antagonismo dos campos onde se

32 eij" th;n tw'n ejleuqevrwn empesovntes ejpisthvmhn (Platão, Sof., 253c). 
situam - o do Ser e o do Não-Ser -, mas, também, a conjugação existente em cada um desses dois segmentos estruturais, a do Ser que se detecta em todo Não-Ser, a do Não-Ser que está presente em todo Ser. Estrategicamente, o filósofo freqüenta, além das instâncias luminosas da oujsiva, o território tenebroso dos seus simulacros para desalojar o sagaz imitador do próprio reduto.

\section{O filósofo e seu perfeito sósia}

O embate entre o filósofo e o sofista terá seu desfecho no único domínio possível de ser comum a ambos, região intermediária onde fluem discursos em acirrada disputa quanto à possibilidade de se pensar e dizer o Não-Ser, o da linguagem. Com a magnificência vazia de seus lovgoi, urdidos a partir de uma visão fragmentária e parcial - "ele te parecerá alguém que fecha os olhos ou que, absolutamente, não tem olhos"33 -, o sofista enunciará uma "meontologia" ao dizer as coisas de modo diverso do que são (e \{tera tw'n o[ntwn) (Platão, Sof., 263b): suas prestigiosas formulações "das coisas que não são" (tav mhv o[nta) são "discursos falsos", outros que os do filósofo (a[llov" lovgo"). E o que o guia e guardião da linguagem visa, em seus altos vôo dialéticos, é vislumbrar, com olhar sinótico, paradigmas ontológicos estáveis para que o método "diairético" possa conduzir a proposições tão perfeitas "quanto uma barra de ferro" (Platão, Sof., 267e).$^{34}$ Dizendo as coisas de conformidade com sua essência, com lovgoi bem entrelaçados aos grandes valores da região luminosa do Ser, o filósofo investe-se de autoridade quanto ao que é veraz. Contra a eloqüência arbitrária do sofista (que diz "coisas que não são" como se fossem "as que são"), instaura a ciência das realidades supremas, destinada a ordenar o discurso filosófico. A dialética, arte de falar corretamente, dizendo "o que é" de acordo com "o que é", pela busca comum dialogada, chega até o ponto exato da demonstração "daquilo que podemos dizer que é a raça e o sangue do autêntico sofista" (Platão, Sof., 268d) e, assim, derrota-o espetacularmente.

33 Dovxei soi muvein h[ pantavpasin oujk e[cein o[mmata (Platão, Sof., 239e).

34 Afirma Gaudin (1990, p.190): "O que é espantoso no emprego dos paradigmas de divisão é a extrema liberdade de sua escolha, uma liberdade tal que tudo se passa como se Platão estivesse convencido que, partindo de um ponto qualquer do universo do Ser, se chegasse, por aproximações sucessivas, à apreensão das determinações particulares dos seres". 
Fazendo vencer, por força da conversação metódica, a mais importante tese da complexa temática do Diálogo - o Não-Ser é e, portanto, é possível pensá-lo e dizê-lo - e, delineando, firmemente, o percurso de todas as decorrências ontológicas até as últimas conseqüências, o filósofo chega à límpida enunciação da essência do sofista. Ele não é nada mais nem nada menos que a outra face do filósofo? No plano teórico, o sofista trata do Não-Ser, dos fenômenos ou dos acidentes, enquanto o filósofo busca perpetuar o Ser e as essências. E, da mesma maneira que entre o Ser e o Não-Ser, ambos, em uma relação binária de coexistência, exercem ação mutuamente diferenciadora na apreensão do próprio reverso. O filósofo, ao definir-se como o mesmo que todos os que buscam um dizer verdadeiro com seus discursos, afirmando "a propósito de ti, coisas que são como elas são", ${ }^{35}$ opõe-se à infinidade daqueles outros, os erísticos, que, com sua habilidade verbal, acabam por fazer um uso falsificador da linguagem, confundindo "o que não é" com "o que é". É assim que Platão, com seu dom de dialético, consegue, finalmente, determinar a enigmática natureza de seu duplo heterogêneo (e, conseqüentemente, sua própria identidade também), caracterizando-a com múltiplas formulações enraizadas na negatividade: se "o que não é" deve ser reconhecido como alguma coisa, tanto quanto "o que é", o sofista é o antifilósofo, o não-filósofo, o diferente dele, o perfeito sósia, aquele que parece ser, mas não é; e que, em seu insólito disfarce, sendo Outro, quer fazer-se passar pelo Mesmo, diante da multidão ignorante que não hesita em identificá-los (Platão, Sof., 216c).

\section{O açodamento do lovgo"}

O esclarecimento das enormes dificuldades relativas à concepção do Ser e do Não-Ser - foi preciso vencê-las termo a termo para poder avançar - permite a Platão descartar, também, embaraços referentes ao ser do lovgo" e a seu valor na representação de um saber filosófico universalmente válido. Para aqueles que refletem com seriedade, será viável, doravante, mais rigor na configuração e na transmissão dos pensamentos que teve após prolongado convívio com as coisas verdadeiras.

O pensamento que fala filosoficamente há dois séculos, sem indagar numa investigação radical o que seja isso, tematiza agora, como tarefa, num gesto inaugural, o ser único e difícil da linguagem, tentando fazer

35 Levgei de; aujtw'n oJ me;n ajlhqh;" ta; o[nta w" e[stin peri; soà (Platão, Sof., 263b). 
sua essência revelar-se por inteiro. O estudo reflexivo de um método fundamentado na discussão que é busca comum, inevitavelmente não teria que deparar com essa questão? A investigação sobre a dialética, nos últimos Diálogos, apresenta-se como extenso arrazoado sobre as proposições, estrutura formal e condições de legitimidade. Platão - em cuja perspectiva a noção de Ser e a realidade que ela recobre, em sua múltipla exemplaridade, é o que há de mais difícil para se conceber e exprimir na linguagem - não coloca problemas de conhecimento em termos de linguagem, e problemas de linguagem em termos de conhecimento?

O que tem levado muitos a odiar os raciocínios e os argumentos, de maneira generalizada, por haver exaurido neles o espírito sem sucesso, tornando-se inimigos da ciência, é a ausência de uma "arte" apropriada. É a dialética que deverá livrá-los da misologiva (a mais grave das fal$\operatorname{tas}^{36}$ ), à qual a afirmação dos erísticos de que "o que é é o que é dito" acaba por conduzir. Como salvaguarda de tão grande mal para a Filosofia, Platão faz do método o principal agente na geração de um discurso rigoroso, fundamentado na sistematização da ordem das identidades e das diferenças: assegura, a um só tempo, a identidade permanente de cada coisa (para que seja ela mesma) e sua diversidade relativa (para que seja outra que as outras) a partir do extremo refinamento de que se reveste com a junção do procedimento das divisões ao das sínteses. Revitaliza a linguagem filosófica ao desdobrar, num grande esquema, uma espécie de tábua de categorias, fundadoras do pensamento e do discurso: uma vez vislumbradas pelo nou'", a vocação do discurso do dialético - sua técnica está baseada no princípio relacional - é chegar à formulação da verdade essencial que lhes é própria, dianoeticamente, com raciocínios e argumentos dotados de clareza. ${ }^{37}$ Estabelece, assim, um modelo fundante que propicia à Filosofia a superação do ponto de declínio, a atemorizadora crise da linguagem provocada pelos ardis da sofística.

Enriquecido da força dedutiva de um segundo movimento, o descenso, o método dialético permite que o pensamento platônico dê o salto decisivo à elaboração de uma teoria ontológica do lovgo", que o livra da precariedade e confere-lhe estatuto epistemológico consistente. Da conciliação do lovgo" com a oujsiva - ordem imperativa que impõe regras de

36 wJ" oujk e[stin, e[fh, o\{ti a[n ti" mei’zon touvtou kako;n pavqoi h] lovgou" mishvsa" (Platão, Fed. $89 \mathrm{~d})$.

37 Empregando a imagem utilizada por Diès e Festugière, Montes (1962, p.173-4) afirma que o esforço metódico de Platão consiste em "transpor" o intuitivo para o racional: a racionalização da Dialética complementa a aquisição intuitiva das Formas mediante o processo da dedução, isto é, de sua inter-relação lógico-ontológica. 
conveniência e de inconveniência para suas formulações - resultaram tanto a definição da verdade como conformidade omoivwsi") entre a proposição (o que é dito) e o objeto da proposição (o que "é"), como, também, a concepção do discurso verdadeiro como exatidão (ojrqovth") da linguagem na referência ao Ser, minimizando as descontinuidades apontadas nos Diálogos do período médio, entre o "ver" e o "dizer". 38 O pensar filosófico é definido, nos últimos Diálogos, como atividade solidária, simultânea e dependente do falar: o mobilíssimo pensamento é o mesmo que o discurso, exceto que é diálogo silencioso da alma consigo, praticado no isolamento, no laborioso exercício da mais alta forma de reflexão humana. ${ }^{39} \mathrm{O}$ pensar é como falar a outro, põe questões e elabora respostas, interioriza um tu imaginário, desencadeando a si próprio o antagonismo discursivo característico da dialética (Wolff, 1992, p.156). ${ }^{40}$

Esse pensar idêntico ao falar pela potência inventiva do jogo relacional que desenvolve - é o mesmo que o entrelaçamento dialógico das tensões antinômicas da "ciência" dialética -, sendo também um Gênero do Ser está apto, pois, a desembocar, intuitivamente, por uma prática persistente, nesse termo último que constitui o eixo de toda dialogação, o mais unificante de todos eles. E, num esforço suplementar pedagógico, por dedução sistemática, procurará transpor, racionalmente, aspectos menos claros para nós dessa unidade superioríssima, explicitando a trama formal toda, urdida por suas infindas incursões e participações na multiplicidade inesgotável dos seres inteligíveis existentes.

\section{Ideal pedagógico do dialético}

A reprodução propositada da aventura interior e silenciosa do pensamento especulativo pela conversa a dois, que constitui, para Platão, a verdadeira experiência filosófica (dialevgesqai), torna manifesto o ideal

38 De acordo com Joly (1974, p.181), a reconciliação do lovgo" com a oujsiva somente é possível com o deslocamento, para o discurso, do destaque inicialmente colocado sobre a visão, na República, onde, sobretudo, o que é visto é que é, podendo se falar, portanto, de uma trilogia ótica, do visível, de quem vê e da luz. No Sofista, o que é é, principalmente o que é dito, o que supõe como condição, o entrelaçamento do Ser, do Mesmo e do Outro, necessária a toda atribuição: pelo entrelaçamento dos gêneros, compreende-se o entrelaçamento dos discursos: dia; ga;r th;n ajllhvlwn tw'n eijdw'n sumplokh;n oJ lovgo" gevgonen hJmi'n.

39 Oujkou'n diavnoia me;n kai; lovgo" taujton: plh;n oJ me;n ejnto" th"' yuch'" pro;" aujth;n diavlogo" a[neu fwnh"' gignovmeno" tou't j aujto; hJm\#h epwnomavsqh, diavnoia (Platão, 263e).

40 De acordo com Robinson (1933, p.52), uma das características essenciais que foram conservadas, persistentemente, nos diálogos do último período é a conversa tipo pergunta-resposta. 
pedagógico de seu método. Se toda pesquisa da verdade tem valor de ensinamento, a dialética, por seu modo de ser, mantendo viva a disposição de enfrentar, sem tréguas, questões difíceis e aparentemente insolúveis, possibilita ao espírito a aquisição da ajrethv própria ao filósofo: é renunciando à pressa e à superficialidade que ela se faz penetrante para enfrentar, com vigor, a prestigiosa habilidade verbal de adversários astutos. Assim conduzida, a paideiva desenvolvida no Sofista faz que o interlocutor (Teeteto) possa transpor, gradualmente, o lugar-comum das conjecturas baseadas nessa forma primeira do saber que é o conhecimento do nome, quanto ao qual é preciso, desde o início, haver acordo entre as partes dialogantes: "até aqui só concordamos, tu e eu, quanto a seu nome, mas a função (e\}rgon) que por esse nome lhe cabe poderia ser, para cada um de nós, uma noção toda pessoal (ijdia')" (Platão, Sof., 218c). ${ }^{41}$

O conhecimento das relações conjuntivas e disjuntivas entre os Gêneros que servirá de fundo filosófico indispensável para que o jovem Teeteto ultrapasse a fase inicial da pesquisa e chegue à definição correta de seu objeto: "o que é preciso fazer agora é nos deixar levar (sunepispwvmeqa) por essa tese (da comunicação entre os Gêneros) e prosseguir na investigação (Platão, Sof., 254c). No decorrer da convivência dialética (sunousiva) - que permitirá a aprendizagem da distinção do discurso do filósofo de sua contrafacção -, pela qual o Estrangeiro ou Sócrates (mais freqüentemente) exercem sua maiêutica purificadora, eles jamais se dirigem aos homens em geral (nem a seus concidadãos, nem a um pequeno círculo de amigos), mas a um indivíduo determinado, ao qual endereçam especificamente suas interrogações (Platão, Sof., 217c-d; 218b). E, enquanto reportam-se "a" (ele), falam "de" (do ser, de algo que o precede), "do que é" - uma vez que o sujeito em todo Diálogo é "isto" do qual se fala (e não aquele que fala) - e que está vindo à luz por meio desse dinâmico falar "com" (Wolff, 1993, p.21).

Usando da maestria de sua arte para tornar mais excelentes os indivíduos, o mais competente diretor de consciências, Sócrates faz-se, também, poeta no original e forte sentido do termo. Pela agilidade de seu fluxo discursivo induz este que está sentado à sua frente a acompanhá-lo no longo trajeto que eleva o espírito a alturas que lhe facultam, sinotica-

41 O ponto de partida, na pesquisa platônica, é a ausência de contradição entre os interlocutores, o acordo que significa um primeiro critério de verdade: "eu sei que isso sobre o que minha alma opina e com o que estarias de acordo, desde o início, seria a verdade" (Platão, Górg., 486d). Porém, numa segunda etapa, esse critério vai ser reconhecido como insuficiente, enganoso, resultante da opinião: a veracidade do julgamento fundamenta-se nas realidades, em si mesmas, estáveis, firmes e imutáveis. 
mente, o surgimento de um universo ontologicamente hierarquizado. Mesmo operando com uma linguagem meramente humana, imprecisa, ele não permanece impotente para apontar, em sua abrangência, os nexos entre esses dois pólos, o do lovgo" e o do Ser: apoiado em rigorosos desdobramentos, característicos do processo das divisões, consegue iluminar nervuras da estrutura constitutiva do real que permaneciam implícitas, a rede de conexões e relações predicativas atribuíveis ao princípio superior. A lição desse genuíno educador é referente ao método, instrui emblematicamente sobre a imperiosa necessidade, para o discurso que se quer filosófico, de um suporte apodítico. Todo conhecimento é conhecimento de algo (Platão, Rep., 476d-477a), tem por objeto um ser que ultrapassa a dimensão do sujeito cognoscente e que funciona como valor-base de indiscutível objetividade: ${ }^{42}$ essa noção difícil de precisar, somente enunciada a muito custo (o pantelw'" o[n) (Platão, Sof., 248e-249d), a maior e a principal (tou mevgistou te kaiv ajrch;gou) (Platão, Sof., 243d), é a mais importante do Diálogo, identificável ao Deus de Platão (Diès, 1926, p.556).

Sair de si mesmo, da relatividade e contradição da subjetividade humana, para fixar seu lugar ao lado desse impalpável vértice, regente e fundante do real; entrecruzar-se com essa presença suprema para adquirir legitimação ontológica e estabilidade essencial suficientes para fazê-la cintilar, como objeto possível, de uma possibilidade permanente (conquanto sempre problematizável), de uma autêntica ejpisthvmh, eis o que o pensar platônico prescreve como tarefa eminentemente pedagógica a seu legado filosófico: ${ }^{43} \mathrm{o}$ cerne dessa complexa paideiva é educar o homem para conhecer a divina ajrchv e a figura matricial dessa árdua yucagwgiva é o dialético.

\footnotetext{
42 Segundo Moureau (1951, p.52), o platonismo é um idealismo que supõe a objetividade da transcendência do Ser, a realidade da coisa que é em si, a Idéia, cuja existência independe do pensamento: nesse sentido, ele é um realismo (1951, p.52). Para Brun (1985, p176-7), a filosofia de Platão tenta encerrar a crise do lovgo" pela qual são responsáveis os sofistas. Entre os pré-socráticos, o lovgo" era linguagem que falava ao homem e à escuta da qual este devia colocar-se (é o que tudo governa", segundo Heráclito (fr. 72); e, sendo depositários dele, a maioria entre os primeiros filósofos fala como profeta ou poeta inspirado: os sofistas cortam qualquer relação do lovgo" com a transcendência pela retórica, provocando sua degenerescência.

43 Segundo Guérin (1979, p.30), a natureza e o destino da Metafísica são existir como um discurso pedagógico, uma vez que é dado, originariamente, como um paravdeigma: todo modelo é da competência da Pedagogia.
} 
SANTOS, M. C. A. dos. The platonic demarcation of news epistemological frontiers to the philosophical discourse: a study of the Sophist. Trans/form/ação (São Paulo), v.24, p.273-299, 2001.

- ABSTRACT: In the Sophist, through the circuits of the ontological-binary procedure of the dialectial divisions, Plato tries to arrive not only at the truth of the things in themselves, but also rigorous methodic treatment, which minimizes its limitations and inadvertences, and locates it in a transcendent dimension, among the types of Being, secures to it the status of philosophical discourse, capable of saying that which is, as it is.

- KEYWORDS: Ancient Philosophy; Plato; language; metaphysics.

\section{Referências bibliográficas}

ARISTÓTELES. Métaphysique. Trad. J. Tricot. Paris: Vrin, 1970.

BRÉHIER, E. La notion de problème en philosophie. In: Études de l'ensemble. Paris: PUF, 1953.

. Histoire de la Philosophie. Paris: PUF, 1967. t.I.

BROCHARD, V. La théorie platonicienne de la participation. In:_. . Etudes de philosophie ancienne et de philosophie moderne. Paris: Vrin, 1974.

BRUN, J. Heraclite. Paris: Seghers, 1969.

Platão. Lisboa: Dom Quixote, 1985.

CASSIN, B. Ensaios sofísticos. São Paulo: Siciliano, 1990.

CORNFORD, F. M. Plato's theory of knowledge. London, Routledge, 1935.

CROMBIE, A. Analises de las doctrinas de Platón. Madrid: Alianza Editorial, 1979.

DIAS, P. S. A filosofia recente e o platonismo. In: CHATELÊT, F. Platão. Porto: Res Editora, s. d.

DIÈS, A. Le Dieu de Platon. In: Autour de Platon. Paris: Beauchesne, 1926. . La définition de l'être et la nature des Idées dans le Sophiste de Platon. Paris: Vrin, 1932.

GAUDIN, C. Platon et l'alphabet. Paris: PUF, 1990.

GOMPERZ, T. Les penseurs de la Grèce. Paris: Payot, 1928.

GUÉRIN, M. Le génie du philosophe. Paris: Seuil, 1979.

JOLY, H. Le renversement platonicien. Paris: Vrin, 1974.

KUCHARSKI, P. Les chemins du Savoir dans les derniers dialogues de Platon. Paris: PUF, 1949. 
MONTES, J. N. La dialectica platonica. Caracas: Universidad Central de Venezuela, 1962.

MOUREAU, J. Réalisme et idéalisme chez Platon. Paris: PUF, 1951.

NADAL, J. Remarques sur le "Parménide" de Platon et la pensée du Non-Être. Revue de Métaphysique et de Morale, n.1, 1984.

PACCI, E. La dialéctica en Platon. In: . La evolución de la dialéctica. Barcelona: Martinez Roca, 1971.

PARAIN, B. La Métaphysique de la parole. Paris: Gallimard, 1969. . Recherches sur la nature et les fonctions du langage. Paris: Gallimard, 1942.

PESSANHA, J. A. M. Platão - O teatro das Idéias. Cadernos de Filosofia da PUC-Rio, n.11, 1997.

PINOTTI, G. E. M. de. Négation, Fausseté et Non-être dans le Sophiste. Revue de Philosophie Ancienne (Bruxelles), n.2, 1994.

PLACES, E de. La langue philosophique de Platon. Études platoniciennes, Leiden: E. J. Brill, 1981.

PLATÃO. Oeuvres complètes. Paris: Les Belles Lettres, 1946-1956. t.I-XII. (Éd. CUF).

ROBIN, L. Les rapports de l'être et de la connaissance. Paris: PUF, 1957.

ROBINSON, R. Plato's Earlier Dialectic. Oxford: Oxford University Press, 1933.

SCHAERER, R. La Question Platonicienne. n.2. Paris: Vrin, 1969.

SCHUHL, P. M. L'oeuvre de Platon. Paris: Vrin, 1971.

STRYCKER, E. de. Notes sur les relations entre la problématique du Sophiste de Platon et de la Métaphysique d'Aristote. Revue Philosophique de Louvain, v.51, 1953.

WOLFF, F. Eros e Logos: a propósito de Foucault e de Platão. Revista Discurso (São Paulo), n.19, 1992.

- Três figuras do discípulo na filosofia antiga. Revista Discurso (São Paulo), n.22, 1993. 